\title{
Dalit Art Forms and Tourism Promotion: Case Study of Theyyam Dance
}

Jacob John* and Megha Jacob ${ }^{\dagger}$

\begin{abstract}
Promotion of Dalit art forms under tourism can contribute to social and economic empowerment of marginalised communities in India. Modern tourism is a strong instrument to reduce the existing power inequalities and discriminations. Theyyam dances in Kerala are now effective tools and weapons to resist and fight back against an unjust social system. Promotion of Dalit art forms under tourism can contribute to social and economic empowerment of these marginalised communities.
\end{abstract}

Key Words: Religious tourism, Sponsor tourism, Seasonal tourism, Dalit art forms

\section{Introduction}

Culture and art forms have become a powerful and liberating communication tool for Dalit in India. Their art forms have been counter-hegemonic discourse in several cases, and have started to enter the popular media and attracted by various segments of the society, especially the middle class. There is a quest among the Dalits to give a new dimension to their cultural art forms like Parayattam, Kaniyattam and Theyyam, affirming their liberation. Their singing, drumming, strumming and dancing re-define Dalit's

* Director, KDS-Delhi ; jacob305@rediffmail.com

${ }^{\dagger}$ Economist, KDS Delhi 
perspective (Goldy 2005).Theyyam dance in Kerala is an effective tool and weapon to resist and fight back against an unjust social system. Several scholars have indicated a strong relationship between tourism and Dalit arts. Simpson and Ladle (2007) has emphasized the need for developing economically viable enterprises that give livelihood support to local communities by promoting indigenous cultures. Promotion of Dalit art form sunder tourism can contribute to social and economic empowerment of these marginalised communities. Modern tourism is a strong instrument to reduce the existing power inequalities and discriminations. There are several such Dalit arts in India today where Dalits expresses their feeling in line with their struggles for rights in relation to caste, class, gender, livelihood, rights, etc. The tourism sector needs to treat the contribution of Dalit and adivasis with respect to arts and handicrafts differently. From an economic perspective of tourism, in the context of employment generation, income generation and creation of livelihood opportunities, tourism has the potential for the development of Dalits in India.

The paper discusses the potentials of promoting artistic or cultural performance of marginalized communities within the framework of tourism promotion, as a tool to reduce or remove the suppression of the Scheduled Castes (SC)/ Scheduled Tribe (ST) in Indian society. The paper analyses various socio- cultural aspects of Theyyam, a dance system which has a close relationship with the social systems and caste structure. This paper utilizes a household survey conducted in Kannur and Kasargode districts of Kerala to analyse health, social and economic problems of Theyyam dancers. It enlists the special interventions required for the up-liftment and welfare of Theyyam dancers through various government programmes, and brings out an action plan for promoting Theyyam as a religious and cultural event within the framework of tourism promotion programmes in India.

\section{Theyyam Dance: A Dalit Cultural Art Form}

Features of Theyyam Dance: It is a dance performanceof a section of indigenous community that combines instruments and vocals. It is a unique art form that blends religious beliefs, art, dance and music. Theyyam, a 40 minutes dance performance, is completely 
devotional both in its ethos and rendition. Artists perform with necessary fasting and preparation as the whole dance programme is a dedication to God. Theyyam is not just a dance but a practice encompassing the twin elements of art and religious devotion. Though it is exclusive to male artists, younger girls below the age of 10 or women above 40 are performers in exceptional cases. Different rituals associated with the dance with different practices like worship of spirit, ancestors, heroes, trees, animals, serpents, Goddesses of the disease and the village deity.

The performer invokes the deity and dances while the singer or artist also recites poems in praise of the deity or narrate the story relevant to the deity. The performance ends with the distribution of 'adayaalam' or 'kuri' (usually rice with turmeric) to the devotees and blessings on them. The assembled devotees in turn offer money to the shrine. The dancers need to undergo rigorous training on the characteristic traits of the deity they play. It is important for dancers to approach physically and spiritually the divine trance in which the Theyyam is performed. The artist is trained by the Chieftain ${ }^{1}$ on all the nuances of the performancesuch as the makeup and songs. Theyyams play an important role in the general life of people in north Kerala as they used to pray to Theyyam God to solve their family problems, health issues, social problems, etc. The performance takes place in the "Kavu" ${ }^{2}$ " or in the courtyards of the Tharavadu ${ }^{3}$. The worship places are decorated with sculptures made of wood. These places are quite different in nature when compared to the other Indian Hindu Temples. God may be represented by a sword, carved stones, a stool, and a piece of wood or mask. The performers wear exotic dresses, colourful costumes and elaborate headgear. The performer wears a skirt or waist dress made of bamboo splices or coconut fronds covered with red cloth, the face and body is carefully

\footnotetext{
${ }^{1}$ Chieftain is an experienced Theyyam dancer who is above 50 years and are not fit for the performance

${ }^{2} \mathrm{Kavu}$, asacredgrove of trees of special religious importance to a Hindu culture.

3 Tharavadu is a Malayalam word which means ancestral home. A person's Tharavadu is used to show her/his root and identity even after living in a different place.
} 
painted with natural dyes and colorful pastes. The painting of the body is varies according to the deity which is being invoked. The head dress or muti is also different for each Theyyam while some of them have 50-60 feet high. These are made of arecanut tree or drumstick tree wood or bamboo splices and decorated elaborately with coloured cloths, coconut leaves, flowers, etc. Ornaments such as wristlets, anklets, necklaces are used.

A Theyyam dance performance is a team effort and three sets of people associated with Theyyam are the dance performer, makeup artist and prop makers. Each team consists of 12 to 15 persons comprising of sacred dance performer, the costume decorator, the face-painter, the craft maker, lamp carrier, makeup man, singer, assistants and instrumentalists. It is quite interesting to understand that all the members of the dance team are experienced with all the activities. They are not separate classes, but are mutually inclusive. The same person can act as the dancer, make up man, or the costume decorator as the case may be. The functional distribution of activities is allocated as per requirements. Prop makers make a wide range of dance materials such as a skirt or waist dress made of bamboo splices or coconut fronds covered with red cloth. The dance performer has to acquire several skills like singing, material making, playing the drums and effective presentation. The presence of mind and ability to take extempore decisions, and also effectively communicate such decisions in order to help settle disputes that are brought before the Theyyam and diplomacy in handling representatives from different communities and positions are required in the dance performance.

Castes and Theyyam Rights: The dance system has a close relationship with the social systems and caste structure. The Theyyam performer, called Kolakkaran or Koladhari, in Malayalam, belongs to SC/ST. Exclusive right to perform dance is given to SC or ST who are from the lower-strata of the society to perform it and people outside prescribed castes are not allowed to perform the dance. People outside prescribed Castes are not allowed to perform the dance. Theyyam performers are mainly from Malayan, Vannan, Mavilan, Vettuvan, Pulayanand Kopalan. Velan, Malayan and Vannan are the predominant communities that have traditionally performed Theyyams. The principal deity in 
Theyyamis Sree Muthappan while there are over 450 varieties of forms of dances depicting various deities. Sree Muthappan Theyyam is performed around the year whereas the other Theyyamsare performed seasonally. In some Kavus the Perum Kaliyattam Theyyam festival is conducted at intervals of 12 or more year.

Theme of Theyyam Dance and Caste Dimensions: Theyyam dances are performed mainly as religious offerings of four major categories of the people. The main and prominent category is the local community. Secondly, a joint family called Tharavadu (ancestral home) also offers Theyyam dances. The third category is a single family. Apart from these categories of offerings in Kerala, non-resident Keralites offer Theyyams in other parts of India and even abroad. The results of our field survey clearly shows that about 95 percent of offerings of dance were made by the local community during 2013-14. Tharavadu (a Malayalam word which means ancestral home) had offered just 2.5 percent dance performances. About 2 percent dance offerings were made by single families. A non-resident outside Kerala had also made offerings.

In an upper caste dominated society, Theyyam came as a platform for positive relationships, interactions and cooperation, between Upper Castes and SC/ST. It is a custom of worship that dates back several thousand years. The words of SC/ST dancers during the Theyyam performance are venerated by the people belonging to upper caste as the Divine Will. Individuals or families belonging to the upper caste sponsor or offer the dance. Whenthe performance ends, the dancers resume their ordinary roles in the lowermost strata of society with no special distinction or recognition. In the past, Theyyam dances were tools and weapons to resist and fight back against an unjust social system as a religious revelation. The result of our field survey clearly shows that the dance influences a section of Upper Castes (21\%) in their positive attitudes towards lower castes. While there are Upper Caste people who refuse to mix with or eat with lower caste, several others (52\%) have started to interact with the dancers in their day-to-day life. It may be noted that, over the last 20-30 years, Theyyam artists have used Theyyam to inspire self-confidence among the members of SC/ST. According 
to 58 percent respondents covered under the survey, members of SC/ST see the Upper Castes bowing down to the deities that have entered SC/ST as a positive and inspiring action. Some of the new generation dancers consider this response from Upper Castes as an encouraging action.

Recently a section of new generation dancershave started showing interest in the performance as Theyyam has made positive impact on their self-esteem as a Theyyam artist. The policy change of CPI (M), the dominant political party in Kannur and Kasargode districts, has also played a significant role in enhancing the level of interest in Theyyam. During 80s and 90s CPI (M) and Kerala Shastra Sahitya Parishat, two atheist organizations had discouraged their members and supporters from performing or sponsoring Theyyam dance performances. As a result, the participation of the new generation had declined. But the situation has undergone a sea change now as both the organizations have found it as a good art form for the new generation. Even the members and supporters of Communist Party perform Theyyam dances as they view it as an art form. Recently there is a revival as this art form is introduced in many universities. Now there is an increased acceptance of this dance form as people wanted to identify themselves as an artist. A segment of multi-national companies have started to sponsor theTheyyam dance as a traditional form of art. These factors have resulted in the enhanced social acceptance of the Theyyam dance.

Table: 1Dance Performers: Reasons for Selecting Theyyam Dance

\begin{tabular}{|l|c|c|}
\hline \multirow{2}{*}{ Main Reasons } & \multicolumn{2}{c|}{ Responses } \\
\cline { 2 - 3 } & Number & Percent \\
\hline Family Traditions with Religious Belief & 111 & 55.5 \\
\hline Family Traditions without Religious Belief & 70 & 35 \\
\hline Livelihood & 18 & 9 \\
\hline Love for Art & 1 & 0.5 \\
\hline Total & 200 & 100 \\
\hline
\end{tabular}

Source: Field Survey

Note: Religious believers and non- believers take up Theyyam dance as part of their family tradition.

Multiple factors have influenced people in the selection of the Theyyam dance as a livelihood: family traditions along with 
religious belief, family traditions without religious belief, livelihood and love for art.

\section{Problems of Theyyam Dancers}

In this section, a wide range of problems of Theyyam dancers are discussed in a comparative perspective. Theyyam dance performances have several serious occupational hazards that adversely affect the health of the performers. Health of a significant number of dance performers has deteriorated after their long involvement in the dance performance. By and large, health deterioration is directly related to the rituals followed by the dancers and their livelihood issues. A dance performer is required to follow certain strict rituals. While some rituals are common to all varieties of Theyyam a few varieties have special rituals which have serious health implications on dance performers. Certain Theyyam performances involve in dangerous activities. In the case of Theechamundi, dancers need to fall in to fire early in the morning. Some Theyyams are performed with fire bowls around the body of the performer. Ottakolam Theyyam performer needs to enter the fire heaps hundred times or so. Puthia Bhagavathy and Kandakarnan Theyyam dancers act with the fire bowls around their body. In Puthiya Bhagavathy, the dancer is required to walk on hot coal repeatedly. Whereas, in Thottunkara Bhagavathy Theyyam, the dancer has to accept and consume animal blood from the sacrifices conducted.

The Theyyam dancer's preparation takes a long duration of time, between 11 to 36 hours to create each costume with bamboo textile and silver decorations, etc. The face painting and preparations on the performance day needs a long time in the range of 4 to 5 hours. The headgears are of different types, some are more than 22 feet high. Rituals start in the previous evening and a rigorous fasting is required. A Theyyam can last more than 12 or even 24 hours during which he may not be able to take food or drink water, putting a strain on his body. During the season, he works continuously day and night for weeks together leading to a lot of pressure on him. Hypertension is a common phenomenon in Theyyam artists. The eye makeup affects the eyes of the performer. Many artistes take alcohol after the dance performances, to 
overcome the strain, but which again has a detrimental effect on his health. As discussed earlier, consumption of alcohol is a prerequisite for a particular variety of Theyyam dance. Blood circulation gets affected due to the Theyyam frame being tied to different parts of the body. Arthritis is another common illness found in performers.

The Theyyam performances are a day and night activity. A Theyyam performer leads a secluded life by observing extreme purity of mind and body. On the Theyyam day and the days before he takes simple vegetarian foods such as simple grains, fruits and tender coconut water to keep his body steady for performing the sacred dances. The major occupational hazards reported by Theyyam dancers during the field survey are reported in Table 2. Most of the dance performers (95\%) have indicated long working hours without proper food and sleep as a serious health problem. According to 62 percent dance performers, income from the dance is quite inadequate and they are engaged to part time job to supplement their income to support the family. This has required over time work and day and night activity resulting into several types of health problems. Prevalence of hyper tension is reported by over 42 percent dance performers. It is significant to understand that eye makeup has caused eye sickness for about 32 percent of the dance performers. Alcoholic addictions (22\%) and rheumatic problems (28\%) are reported by dancers.

Table 2 Theyyam Dancers: Major Occupational Hazards and Health Problems

\begin{tabular}{|l|c|}
\hline \multicolumn{1}{|c|}{ Occupational Hazards } & $\%$ \\
\hline $\begin{array}{l}\text { Working Hours for Dance Performance:12 - 24 hours without any } \\
\text { break, proper food, sleep }\end{array}$ & 95 \\
\hline $\begin{array}{l}\text { Along with Dance performance, Additional Livelihood Activity to } \\
\text { support the family resulting in health problems. }\end{array}$ & 62 \\
\hline Hyper Tension & 42 \\
\hline $\begin{array}{l}\text { Eye makeup affects the eyes of the performer adversely, resulting } \\
\text { in eye sickness }\end{array}$ & 32 \\
\hline Rheumatism & 28 \\
\hline Arthritis & 33 \\
\hline $\begin{array}{l}\text { Dance performers drink alcohol on a regular basis to overcome } \\
\text { the strain: Alcoholic addiction }\end{array}$ & 22 \\
\hline
\end{tabular}


It is found that about 22 percent dance performers, who had consumed alcohol on a regular basis to overcome the strain, became alcohol addicts. About 33 percent have reported Arthritis as a common illness found in performers. It may be noted that blood circulation gets affected due to the Theyyam frame being tied to different parts of the body. It is quite clear that several factors take a toll on the performers' health. Although there are no clear evidence to support claims of low life expectancy, the working age of Theyyam dancers has reduced significantly as they stop working at the age of 45-50 years.

Table3Problems of Theyyam dancers in a Comparative Perspective (\%)

\begin{tabular}{|l|c|c|c|}
\hline \multicolumn{1}{|c|}{ Health Problems } & $\begin{array}{c}\text { SC/ST } \\
\text { Theyyam } \\
\text { Dancers }\end{array}$ & $\begin{array}{c}\text { SC/ST Non- } \\
\text { Theyyam } \\
\text { Dancers }\end{array}$ & $\begin{array}{c}\text { Upper } \\
\text { Castes }\end{array}$ \\
\hline Eye sickness & 32 & 2 & 3.5 \\
\hline Hyper Tension & 42 & 10 & 12 \\
\hline Alcoholism & 12 & 2 & 4.5 \\
\hline Rheumatism & 28 & 7 & 6 \\
\hline $\begin{array}{l}\text { Overtime work for } \\
\text { livelihood }\end{array}$ & 62 & 6 & 3 \\
\hline
\end{tabular}

\section{Source: Field Survey}

Performers do not have group or individual health insurance protections. As a result, many of them do not get timely treatment for diseases. Chronic ill health cases such as Rheumatic disorders are reported by a large number of Theyyam dancers. Theyyam dancers have been undergoing a struggle for livelihood and fighting for their survival with acute poverty and poor health. While the earning from Theyyam activities remains abysmally low, they cannot afford to have a minimum standard of living. They are compelled to engage in other activities to supplement their meager income from Theyyam. Some of these dancers, after spending the whole night in a dance performance continue to work in other fields during the day time. A few Theyyam dancers work as private bus assistants on a daily wage basis. They do not get time to take any rest. About 89 percent dancers are the single source of income for their respective families and they need to engage in other part 
time jobs during the day time and off season. A serious concern for Theyyam dancers is the lack of coverage of any social security system, especially health insurance.

The results of the analysis of health problems of Theyyam dancers in comparison with SC/ST non-dancers and with upper castes are presented in Table 3. About 32 percent Theyyam dancers covered under the survey have reported eye sickness against 2 percent SC/ST non- dancers and 3.5 percent upper castes. About 42 percent Theyyam dancers covered under the survey have reported hypertension against 10 percent SC/ST non-dancers and 12 percent upper castes. In the case of other health problems such as alcoholism, rheumatic problems and overtime work for livelihood Theyyam dancers covered under the survey have reported much higher level of prevalence compared to the other two categories. It is quite evident that the health problems reported by Theyyam dancers are not prevalent among other sections covered under the survey. The physical exertion of the performer, the engagement with harmful substances such as alcohol and handling fire cause stress on the mental health of the dancers. Social discrimination also causes some level of mental agony. Low self-esteem of the dancer is a prospective risk factor for depression. It is also found that a small section of dancers' children have low level of selfesteem. The performance of Theyyam dance has affected the health status of Theyyam dancers adversely.

\section{Promotion of Theyyam, A Dalit Art Form: Potentials and Strategies}

In view of its uniqueness as a Dalit art form and various cultural dimensions there is a good scope for promoting Theyyam dance in India. However, special interventions are required for the promotion of the art form and the uplift and welfare of Theyyam dancers.

Ministry of Tourism and Ministry of Culture: The prevailing health, social and economic problems of Theyyam dancers compel their children to engage in more economically viable and less strenuous livelihood and career. The new generation is not enthusiastic in taking Theyyam as a livelihood. This would lead to 
diminished number of artists and ultimately the loss of a unique cultural phenomenon that is a part of the heritage of SC/ST as well as India. Theyyam is not in the professional art list though it has several unique features. The new generation should be encouraged to learn and perform the art. The cultural dimensions of the Theyyam dance should get adequate significance and there is a need for promoting Theyyam dance as a traditional dance. In this context, it is important to provide necessary support by the Ministry of Culture to promote Theyyam dance as a cultural programme. There is a good scope for promoting Theyyam under the category of sponsored tourism. It can be promoted under the category of religious tourism also. It needs a special focus as an art to be promoted as an item for seasonal tourism. Ministry of Tourism, Government of India and Department of Tourism, Government of Kerala should take appropriate measures to promote Theyyam dance.

\section{Empowerment of a Weaker Community through Identification} and Promotion of Cultural Heritage in India: A medium of artistic or cultural performance can be effectively used as a tool to reduce or remove the suppression of the SC/ST in a society. Theyyam dance performance is the mixture of playfulness and seriousness and,the worship of a Theyyam deity results in unifying society rather than dividing it. For example, in 'Pottan Theyyam' the performer abuses, reviles and even physically manhandles the highest authority with unusual anger. Theyyam-performer, in trance, speaks out the frustration and resentment of his community. Sometimes the performer cracks jokes, which would make the devotees laugh, even as the performer plays with fire. At the same time he will make serious criticism. In certain stage of the dance he enacts the collective wish of the community he represents. In all forms of Theyyam dance the words of SC/ST dancers during the performance are venerated by the upper castes as the Divine Will. Through the medium of trance, the dancer who represents deity of the respective Theyyam acquires a voice and are able to speak directly to the Upper Castes against social injustices. It is quite evident that Theyyam dance has become a strong medium for spreading the message of social equity and social harmony in Kerala. Theyyam has become a platform for positive relationships, interactions and cooperation, between upper castes and SC/STs. A 
section of new generation dancers has started to show interest in the performance as Theyyam has made positive impact on their self-esteem as a Theyyam artist. Theyyam dances are now effective tools and weapons to resist and fight back against an unjust social system through a religious revelation during a particular dance performance which influences a considerable section of upper castes in their positive attitudes towards lower castes. State governments with the support of local government institutions and civil society organizations can identify traditional art forms or cultural heritage of SC/ST. In every state there may be similar artistic or cultural performance of SC/ST which must be identified and promoted in an effective way.

Popularisation of Art and Honoring Theyyam Artists: There is no written document for training new artists and currently the training is dependent mainly on the knowledge that is transferred from generations to the head of the families. Documentation of the rituals and customs of the training methodology is very important. Various aspects of dances especially the songs and stories have to be recorded in a form that enables the dancers to share it with the future generations. Proper orientation needs to be provided to the dancers in order to reduce their work pressure and exhaustion. Steps may be taken to organize programmes for interested people on different dimensions of Theyyam Dance. This will help them in acquiring the skill and enable them to become dance professionals. At present, conflict of interest exists between the new and the old generation of dancers as there is a divide between the old school of thoughts and new school of thoughts. There are new developments in this art form like introduction of Mudras, which, for the sake of more acceptance should be familiarized among the dancers. Modernization and commercialization of the art form has also started among the new generation of educated artists. This new generation, which is educated, hold a view that the art-form should be moved from the current confined enactment to a more open and wide panorama as it will create more opportunity for the artists and popularize the art. But this view has been opposed by the orthodox people who are in the age group of 60 and above, as they do not want to move away from the traditional set up. Appropriate promotional activities, with the support of relevant ministries and departments, can address these issues. Promotional 
activities, especially measures such as honoring Theyyam Artists like any other art forms, can attract new generation of the Theyyam families.

Insurance, Pension and Other Welfare Schemes: At present Theyyam dancers are quite vulnerable to various uncertainties and no support system is available to ailing Theyyam artists during the fag end of the career. They do not get the benefit of any social security system. It is important to provide them the benefit of a regular pension scheme. Currently a meager amount of Rs.800 is being given by the state government of Kerala as financial support to Theyyam dancers. The present financial help should be converted into a regular pension scheme. A minimum of Rs.3,000 should be given as a monthly pension to all the Theyyam dancers when they reach the age of 50 years irrespective of their financial status. Most of the Theyyam dance format is very risky and involves tremendous physical exertion and hard work. Considering the high risk, a proper insurance coverage, risk allowance and medical insurance scheme should be made available to Theyyam dancers. Theyyam dancers need special attention especially with respect to the education of their children. The amount of student scholarships and lump sum grant to the students should be revised periodically. A scheme for providing financial help for marriage of daughters of Theyyam dancers may also be set up. A contributory welfare fund may be devised for Theyyam artists. Appropriate steps may be taken to create a welfare fund for Theyyam dancers. Accordingly, temples can set aside a specific amount of money for a welfare fund, to which the artists can also contribute after each performance. This can be used to help artists when they are forced to retire due to ill health or old age. A welfare fund can help many artists to address their financial and health problems. As Theyyam dancing is quite a seasonal activity most of the artists depend on five to six months earnings for their household expenditure of the entire year. An attractive scheme may be devised to provide a livelihood support. The scheme should encompass interest free loans, training programmes, marketing support, etc. The livelihood projects can include setting up of craft centres for making jewellery and other ornaments, fabric making units for costumes, etc. 


\section{Conclusions}

Most of the major states such as Uttar Pradesh, Bihar, Andhra Pradesh and Gujarat have reported increasing number of atrocities against SC and ST during 2001-2012 period (RTI Foundation of India, 2014). Serious and strong measures taken by different State and national governments could not prevent the growing atrocities against SC and ST. In modern India, using artistic and cultural heritage of local community can be an effective technique in reducing atrocities and discrimination against SC/STs. The experiences of Theyyam dance, a popular Dalit art in the northern part of Kerala deserves to be shared with other Indian States by promoting Theyyam as a religious and cultural event within the framework of tourism promotion activities in India. Expression of the reaction and responses of the SC/STs and spreading the message of social harmony and social equality can be made in a professional manner through popularizing Theyyam dance. Concrete measures with the active involvement of Ministry of Culture and Ministry of Tourism, Government of India and, Department of Tourism, Government of Kerala are required for the promotion of the art form and the upliftment and welfare of Theyyam dancers.

\section{References}

Bhattacharya. A. (n.d.). Community Empowerment through Creative Industries and Tourism. Retrieved on October 05, 2015, from www.banglanatak.com

Goldy, G. M. (n.d.). Cultural History and Emergent Dalit Alternatives. Retrieved 2015, from www. countercurrents.org

Kannan, Y. V. (2011). Heyyangalum Anushtanangalum Oru Pattanam (Malayalam). Kerala: Kerala Basha Institute.

Kerala Sangeeta Nataka Academy, (2000). Theyyam, Trissur

Nagarajan. S. Close Encounter with Theyyams, Retrieved on 4 August 2012, from http:/ / www.Hindu.com.

RTI Foundation of India. (2014) Retrieved on 04 July 2015 from www.rtifoundationofindia.com, 
Simpson, M. C., \& R. L. (2007). Implementing sustainable tourism indicators for destinations using a quantifiable Tourism Sustainability Index. Journal of Sustainable Tourism. 